\title{
Pyloric Gland Adenoma
}

National Cancer Institute

\section{Source}

National Cancer Institute. Pyloric Gland Adenoma. NCI Thesaurus. Code C43526.

A rare neoplastic polyp that arises from the stomach. It is characterized by the presence

of gastric epithelial differentiation and pyloric gland-type tubular structures, which are closely packed. 